\title{
Empoderamento e equidade de género: os desafios atuais da mulher moçambicana
}

\author{
Gender empowerment and equity: the current challenges of mozambican \\ women
}

\author{
Diago Tendai Chingore \\ Doutorado em Filosofia \\ Universidade UniLicungo \\ Moçambique \\ ttendaigamachingore@gmail.com
}

\begin{abstract}
"Rebaixar os homens, é a maneira mais infalível para torná-los inúteis. A escravidão e o tráfico negreiro degradaram tanto os donos quanto os escravos. Endureceram seus corações, apagaram a moral, dissiparam a dignidade humana aos quatro ventos, fizeram com que se esquecessem de que Deus criou o homem à Sua imagem." (In. Dadiarra Sheike Modibo \& Cheikh Moustafa B. Ndiaye).
\end{abstract}

Resumo: O presente artigo objetiva debruçar sobre "empoderamento e equidade de género: os desafios actuais da mulher em Moçambique". A representação política delas pode ser vista com um processo contínuo de disputas, controvérsias e, nas últimas décadas, de alguns progressos em termos de igualdade formal. Significa que, atualmente, a mulher possui o direito legal de participar e representar as instâncias políticas. A mulher contemporânea, a partir de suas conquistas nos vários aspetos sociais, culturais, econômicos e políticos, depara-se com a necessidade de reformular seus papéis no desempenho de tarefas relacionadas ao casamento, à maternidade, à família, à sexualidade e à sua carreira profissional. $\mathrm{O}$ objetivo central é analisar as contribuições feitas pelas mulheres para o seu empoderamento e equidade de género, olhando para os principais desafios que elas enfrentam hoje. A contribuição dos seus ideias para as mulheres moçambicanas deve-se, por um lado, a fatores institucionais como a democratização, as quotas de género e os sistemas eleitorais; por outro, os novos movimentos de mulheres, regionais e internacionais, que ressurgiram no início da década de 90, marcaram o debate da Conferência sobre as Mulheres em Beijing. A pesquisa é basicamente teórica, partindo da análise bibliográfica das obras que versam sobre o assunto, acompanhada da desconstrução que permitiu a leitura, interpretação e compreensão dos textos. Como resultados, esperamos que o texto possa contribuir positivamente para repensar Mondlane, hoje, atendendo a ideia de emancipação, empoderamento económico e equidade de género da mulher moçambicana que teve este ativista como seu promotor principal e os primeiros passos da construção de uma educação para todos.

Palavras-chave: Emancipação. Empoderamento. Equidade de género. Mulher moçambicana.

Abstract: This article aims to address "gender empowerment and equity: the current challenges for women in Mozambique". Their political representation can be seen with a continuous process of disputes, controversies and, in recent decades, some progress in terms of formal equality. It means that women currently have the legal right to participate and represent political bodies. Contemporary women, from their achievements in various social, cultural, economic and political aspects, are faced with the need to reformulate their roles in the performance of tasks related to marriage, motherhood, family, sexuality and their career professional. The central objective is to analyze the contributions made by women to their empowerment and gender equity, looking at the main challenges they face today. The contribution of his ideas to Mozambican women is due, on the one hand, to institutional factors such as democratization, gender quotas and electoral systems; on the other, the new women's movements, regional and international, 
which resurfaced in the early 1990s, marked the debate of the Conference on Women in Beijing. The research is basically theoretical, starting from the bibliographic analysis of the works that deal with the subject, accompanied by the deconstruction that allowed the reading, interpretation and understanding of the texts. As a result, we hope that the text can contribute positively to rethink Mondlane, today, taking into account the idea of emancipation, economic empowerment and gender equity of Mozambican women who had this activist as their main promoter and the first steps in building education for all.

Keywords: Emancipation. Empowerment. Gender equity. Mozambican woman.

Cite como

(ABNT NBR 6023:2018)

CHINGORE, Tiago Tendai. Empoderamento e equidade de género: os desafios atuais da mulher moçambicana. Dialogia, São Paulo, n. 37, p. 1-19, e17592, jan./abr. 2021. Disponível em: https://doi.org/10.5585/dialogia.n37.17592.

\section{American Psychological Association (APA)}

Chingore, T. T. (2021, jan./abr.). Empoderamento e equidade de género: os desafios atuais da mulher moçambicana. Dialogia, São Paulo, 37, p. 1-19, e17592. https://doi.org/10.5585/dialogia.n37.17592.

\section{Introdução}

O presente artigo objetiva debruçar sobre "empoderamento e equidade de género: os desafios atuais da mulher em Moçambique”. A representação política delas pode ser vista com um processo contínuo de disputas, controvérsias e, nas últimas décadas, de alguns progressos em termos de igualdade formal. Significa que, atualmente, a mulher possui o direito legal de participar e representar as instâncias políticas.

A participação política designa uma grande variedade de actividades, tal é o caso de eleger, candidatar-se a algum cargo eletivo, apoiar um candidato ou uma agremiação política, contribuir financeiramente para um partido político, participar de reuniões, manifestações ou comícios públicos, proceder à discussão de assuntos políticos. O objetivo central é analisar as contribuições feitas por mulheres para o seu empoderamento e equidade, olhando por seu turno, para os principais desafios que elas enfrentam hoje.

Neste âmbito, Moçambique comprometeu-se, internacionalmente, na promoção da igualdade do género através da ratificação da Convenção para a eliminação de todas as formas de discriminação contra a Mulher (CEDAW), da Declaração do Género da SADC, e dos Protocolos da Carta Africana dos Direitos Humanos e dos Direitos da Mulher Africana - conhecida por Protocolo de Maputo (Serra, 2007). De igual modo, Moçambique ratificou vários tratados sobre os direitos das mulheres, e, aprovou várias políticas de género, em princípio assumidas pelo governo, para promover a participação da mulher nos processos de desenvolvimento. 
Foi através da Constituição de 1990, que veio a ser aprofundada com a Revisão Constitucional de 1996 e com a Constituição de 2014, veio consagrar o pluralismo político e separação de poderes, permitindo a criação de um Estado de Direito Democrático, uma Constituição que atende às recomendações das Nações Unidas para o aumento da presença feminina nos órgãos de decisão política.

Nos períodos das guerras, seja a de 16 anos e as subsequentes, as mulheres continuaram a desempenhar um papel importante, razão que levou, por exemplo, a criação de uma divisão especial para as mulheres fornecendo uma formação militar a mulheres. No entanto, a realidade das mulheres era frequentemente diferente da realidade dos homens. $O$ abuso sexual contra as mulheres era comum no exército, e, as mulheres eram frequentemente limitadas em termos de participação na guerra civil, apenas realizando tarefas domésticas, tais como limpeza, cozinhar e cuidar de crianças e de soldados feridos (Mail \& Guardian África).

No final da guerra civil, em 1992, e com o início da fase de democratização, tendo as primeiras eleições multipartidárias sido realizadas em 1994, ocorreu uma segunda mudança de paradigma. O sistema democrático abriu espaço para um debate político sobre os direitos da Mulher (Conceição, 2010). Desde então, a igualdade de género tem sido mais destacada, tanto na agenda política nacional como internacional, e em Moçambique a representação da Mulher na política tem melhorado progressivamente.

A Plataforma de Acção, aprovada na $40^{a}$ Conferência Mundial sobre a Mulher, que teve lugar em Beijing, no ano 1995, identificou os efeitos dos conflitos armados nas mulheres como sendo uma área especial de preocupação e que requer a acção dos governos e da comunidade internacional, e salientou a necessidade da promoção da igualdade de participação das mulheres na promoção da paz, facto que não tem sido observado em várias nações.

Como tese para nossa reflexão, acreditamos que as mulheres têm sido protagonistas seguindo dois caminhos complementares, um na esfera nacional e outro na arena internacional. Neste caso, refere-se aos princípios constitucionais do País e a Declaração dos Direitos do Humanos. Por sua vez, apesar dos significativos avanços obtidos na esfera constitucional, ainda persistem, no imaginário social moçambicano elementos sexistas e discriminatórios com relação às mulheres que são impedidas de se envolverem no processo da promoção da paz com plena autonomia e dignidade.

Contudo, a mulher contemporânea, a partir de suas conquistas nos vários aspectos sociais, culturais, econômicos e políticos, depara-se com a necessidade de reformular seus papéis no desempenho de tarefas relacionadas ao casamento, à maternidade, à família, à sexualidade e à sua 
carreira profissional. O objectivo central é analisar as contribuições feitas por Mondlane em torno do papel da mulher no país. A contribuição dos seus ideias para as mulheres moçambicanas devese, por um lado, a factores institucionais como a democratização, as quotas de género e os sistemas eleitorais; por outro, os novos movimentos de mulheres, regionais e internacionais, que ressurgiram no início da década de 90, marcaram o debate da Conferência sobre as Mulheres em Beijing. A pesquisa é basicamente teórica, partindo da análise bibliográfica das obras que versam sobre o assunto, acompanhada da desconstrução que permitiu a leitura, interpretação e compreensão dos textos.

A história de Moçambique é muito anterior à chegada dos portugueses e, muito distante do que muitos divulgam, os povos que foram enviados por força da colonização portuguesa tinham sua organização em estágio, muitas vezes, mais adiantado que outros povos da mesma época e que, como consequência de uma colonização predatória, tiveram seus futuros interrompidos. Em suma, todo este saber nos tem sido negado fortemente aliado ao colonialismo anterior e ao neocolonialismo actual.

\section{A questão da mulher, emancipação, engajamento e equidade}

As concepções divulgadas no século XVII reforçaram a imagem da mulher como um ser sem vontade própria. Rosseau, apud Gaspari (2003, p. 29), “detinha um discurso de que a educação feminina deveria ser restrita ao ambiente doméstico, pois, segundo ele, não deveriam ir em busca do saber, considerando contrário à sua natureza”. Essa sociedade que lutava tanto por liberdade, passou a exigir que as mulheres fizessem parte dela, mas como mães, guardiãs dos costumes, e como seres dispostas a servir ao homem.

Assim sendo, o debate sobre a mulher, o seu papel no engajamento, emancipação e equidade foi palco e continua em aceso debate em todo os fóruns nacionais e internacionais. Importa referir que a situação da opressão e da discriminação senão marginalização em que sempre esteve a mulher africana, em geral, e a moçambicana, em especial, esta temática é pensada partindo de uma perspectiva e de modelos teóricos heurísticos que nada têm haver com a nossa realidade.

No séc. XVI, utilizando-se de oportunidades que foram sendo oferecidas, como a frequência a salões, onde podem se aproximar dos poetas, escritores e palestrastes, algumas mulheres conseguiram firmar-se no mundo intelectual.

Para tentar, talvez, isentar- se da responsabilidade de ter sido autora da desigualdade social e política na sociedade, implantou-se uma visão cultural de que a mulher é inferior ao homem e não pela educação que lhe foi negada. Essa visão não igualitária entre seus, que preconiza o 
masculino com base em preconceitos e estereótipos, provavelmente, foi responsável pela consolidação de uma sociedade machista nos séculos XIX e XX.

Ao analisarmos as ideias dos filósofos mencionados, fica evidente que no "período das luzes", uma característica marcante foi a de pensar a diferença feminina, acentuada pela inferioridade, baseada no direito natural. No imaginário dos filósofos, não havia necessidade alguma de conferir à mulher um estatuto político, pois, para a ideologia do séc. XVIII, o homem era a causa final da mulher.

Devido às ideias iluministas, o romantismo favoreceu o desenvolvimento e a expressão do amor em todas as suas formas. Nota-se a descriminação, consolidada pelo discurso da mulher frágil, emotiva, amorosa, incapaz, portanto, “inferior”, não permitindo o acesso ao conhecimento dessa condição opressiva. Já no Séc. XIX, surge um novo discurso filosófico sobre a mulher. Com as manifestações contra discriminação feminina e a luta pelo direito ao voto, acontecimento que prevê uma melhoria na perspectiva da forma de viver das mulheres.

Nietzsche considera a mulher como “ser” fracassado que busca elevar-se alterando seus padrões próprios de conduta na sociedade. Dá ao homem a responsabilidade de manter a mulher dependente e sob seu domínio. Assim, ele entende que o homem tem de “... conceder a mulher como "posse" como propriedade a manter sob sete chaves, como algo destinado a servir e que só então se realiza (NITZSCHE, 1992, p.143).

O envolvimento da mulher na política, além de representar uma das formas de combate às desigualdades de género, tem como finalidade o enfraquecimento do grande desafio de fortalecer e ampliar a participação feminina nos espaços de poder e decisão. Pode-se perceber que as mudanças promovidas nesse campo estão articuladas às dimensões sociais, culturais, educacionais, legislativas e institucionais que, aos poucos, reverte o quadro de sub-representação limitado ao cumprimento legal relativo às quotas de candidaturas para as mulheres.

De acordo com Iglesias (2007, p. 4), "os primeiros escritos que retratam a situação da mulher como mãe ou como menina (que necessitava de estudar e preparar-se para a vida futura, longe dos vícios da sociedade) podem ser lidos num jornal de Lourenço Marques, hoje Maputo, intitulado "O Brado Africano", publicado em 1919 a 1974, por um grupo de "homens de cor" que associavam em defesa da "causa africana".

Mas é, sem dúvida, no contexto da Luta de Armada de Libertação Nacional que foram feitas importantes reflexões e estudos que se consideram "mais profundos" da situação da mulher em Moçambique; pelo tratamento da problemática dos obstáculos à emancipação, pela estratégia 
de inclusão da mulher nos centros de decisão e pelo envolvimento da mulher na tarefa principal, a de combater pela independência de Moçambique, como igual, livre e irmã (Idem, 2007, p. 6).

Uma das preocupações fundamentais da FRELIMO era a mulher moçambicana, e este constituiu um dos problemas que mais preocupou a organização. A ideia da emancipação foi levada tendo em conta as seguintes questões: Que tipo de combate deveria ser desencadeado para que a mulher liquidasse os males que a oprimiam? Como definir os inimigos essenciais da mulher em geral e da mulher moçambicana em particular? Uma das características da mulher são os complexos de inferioridade que destroem a sua capacidade de iniciativa. Para Machel (1973, p. 4), "toda mulher tem seus complexos. Tem um ponto comum que é a complexidade. O estado de conflito, muita das vezes, o espírito de conflito paira entre elas". O projecto emancipatório que se pretendia estava aliado à nova sociedade, e esta seria constituída por mulheres de todas as raças e cores. Essa seria a característica de Moçambique.

A característica essencial desta nova sociedade é formada por as mulheres de todas as raças e cores, aquelas que morrem, sofrem, vivem e participam na reconstrução nacional e lutam pela edificação da nova sociedade (MACHEL, 1973, p. 8). O ponto de partida seria a libertação, mas esta não significa para nós simplesmente a expulsão dos portugueses, significa reorganizar a vida do país e lançá-la na via do sólido desenvolvimento nacional. Para isto é necessário tirar o poder político das mãos dos portugueses, visto que estes se opuseram sempre ao seu progresso social e estimularam somente aquele desenvolvimento económico que podia beneficiar uma elite pequena e quase exclusivamente estrangeira. Mas no movimento de libertação não poderá reivindicar o êxito até que, através dele, o Povo consiga o que os portugueses lhe recusaram isto é:

- Em primeiro lugar, o nível de vida tolerável;

- Em seguida, a instrução necessária;

- Terceiro, as condições de desenvolvimento económico e cultural; e,

- Por fim, oportunidade de participar no seu próprio governo” (VVaa, ano, p.8).

Em seu texto "Pode o Subalterno falar?", a escritora indiana Gayatri Chakravorty Spivak procura o sentido atribuído à palavra representação nos contextos político, económico e social tanto para quem representa, como para os que são representados, bem como a questão da consciência e da conscientização da resistência da e na subalternidade (SPIVAK, 2011, p. 2). O sujeito subalterno, na perspectiva de Spivak, é aquele pertencente "às camadas mais baixas da sociedade constituídas pelos modos específicos de exclusão dos mercados, da representação 
política e legal, e da possibilidade de se tornarem membros plenos no contexto do estrato social dominante" (Ibidem, p. 12).

Nesse contexto, há uma constatação do poderio masculino no âmbito da produção colonial, e a autora sinaliza quer reflectir sobre a "mudez" feminina, assim não pode restringir-se a uma simples questão idealista, como também configurar-se num exercício de fala e de reposicionamento da mulher no espaço social. Assim sendo, neste cenário emancipatório da mulher, o "silêncio é resistência".

Para Casimiro (2014, p. 172), “a nova sociedade, criada após a independência, encerra rupturas com a sociedade colonial, mas também dá continuidades ao produto do passado histórico misturando dimensões tradicionais e coloniais que se retroalimentam, numa fase de desordem social, em direcção a uma "sociedade de tipo novo". Já na visão de Mondlane, entende que;

O movimento nacionalista não surgiu numa comunidade estável, historicamente como uma unidade linguística, territorial, económica e cultural. Foi a dominação colonial que deu origem à comunidade territorial e criou as bases para uma coerência psicológica, fundada na experiência da discriminação, exploração, trabalho forçado e outros aspectos da dominação colonial (MONDLANE, 1995, p. 87).

Entretanto, as reivindicações feitas pelos nacionalistas moçambicanos, contribuíram para a criação de associações, sociedades, que através de poesias ou jornais, como o Brado Africano ou o Africano, conduziram às campanhas contra os abusos do colonial, exigindo direitos iguais e, a pouco a pouco, denunciando o sistema colonial.

Contudo, a actuação das mulheres no processo revolucionário foi antecedida pela sua participação em movimentos contra o colonialismo. Antes mesmo do início da luta armada, camponesas cumpriram um papel estratégico na propaganda anticolonialista. E essa experiência também foi vivenciada por grupos femininos das zonas urbanas, estudantes das cidades de Maputo e Xai-Xai, que atuavam no Núcleo dos Estudantes Secundários Africanos de Moçambique (NESAM), de onde saíram lideranças que compuseram os primeiros quadros da Frelimo (ISAACMAM e STEFHAN,1984, p. 22).

O NESAM foi responsável por suscitar em um grupo de mulheres a vontade de se aliar à causa da independência. Porém, algumas delas, não satisfeitas com a distribuição de panfletos, chegaram ao manuseio de armas - foi o caso de Josina Machel, da província de Inhambane, que se inseriu na Frelimo em 1965. Sua atuação nesta organização permitiu-lhe ocupar espaços superiores, como a chefia do Departamento de Relações Exteriores e Assuntos Sociais, prestando assistência, em especial, às causas das mulheres integrantes, ou não, da Frente de Libertação - 
quando uma de suas iniciativas foi a criação de orfanatos para os filhos das combatentes (ISAACMAM e STEFHAN, 1984, p. 23).

$\mathrm{Na}$ mesma perspectiva Isabel Casimiro, entende que;

\begin{abstract}
A iniciativa de formar um exército feminino partiu das próprias mulheres. Desde 1965, um grupo de mulheres camponesas havia solicitado treino militar à Frelimo com o intuito de defender as populações que se encontravam sob sua responsabilidade, tornando-se o primeiro Destacamento Feminino, apesar dos documentos e notícias mencionarem a sua criação apenas no ano de 1966, em uma reunião do Comitê Central. Isto demonstra que, ao menos em princípio, o motivo da reivindicação feminina para combater não se fundamentou em uma formação política, mas na necessidade que sentiram estas camponesas de se unirem em torno de uma causa coletiva para o seu bem e o de suas famílias (CASIMIRO, 2004, pp. 52-54).
\end{abstract}

Entretanto, muitas mulheres que não se inseriram no Destacamento Feminino continuaram a contribuir com a Revolução através de outras formas, como por exemplo: no transporte de material; na produção de alimentos para as (os) combatentes; como informantes, professoras ou enfermeiras. Nesse sentido, "um caso memorável foi o de uma carregadora de equipamentos que, mesmo depois de ter constatado que seu filho atado ao seu corpo havia falecido, em decorrência de ter sido atingido por uma explosão durante o percurso, não deixou de prosseguir o seu caminho, cumprindo a missão de entregar o armamento que carregava à Frelimo" (Tempo, out. 1982, p. 13).

Para a emancipação e empoderamento da mulher em Moçambique, existiram várias divergências, atendendo que surgiram novos exploradores que se opunham, de forma clara e aberta, à justa política de emancipação da Mulher. Eles rejeitavam a participação desta na luta armada. Entretanto, a campanha contra o projecto emancipatório era uma expressão da mentalidade retrógrada dos novos exploradores. Assim sendo, “caluniavam da maneira mais grosseira e brutal as mulheres que se integravam ao Departamento de Defesa, declaravam-se defensores da moral para condenar as mulheres que participavam da luta (MACHEL, 1977, p. 19).

Apoiando-se nas tradições mais reacionárias, eles se erguiam para defender as formas mais degradantes da opressão da mulher: o casamento prematuro, a poligamia, o lobolo, a amantização mesmo com crianças. Diante deste cenário, os reacionários utilizaram as suas esposas para criar uma organização chamada LIFEMO. Esta organização, da qual estavam excluídas as verdadeiras militantes, revelou-se um grande obstáculo ao projecto emancipatório da Mulher, um meio pelo qual, visava manter afastada da sua participação activa na luta (MACHEL, 1977, p. 19).

O projecto da emancipação da Mulher não é um acto de caridade, não resulta duma posição humanitária ou de compaixão. A libertação da Mulher é uma necessidade fundamental da Revolução, uma garantia da sua continuidade, uma condição do seu triunfo. Portanto, a Revolução 
tem por objectivo essencial a destruição do sistema de exploração, a construção duma nova sociedade libertadora das potencialidades do ser humano e a reconciliação desta com o trabalho, a educação, a política, a economia, entre outras tarefas que se adequam à natureza. É dentro deste contexto que surge a questão da emancipação da Mulher em Moçambique (Ibidem, p. 75). Olhando duma forma mais abrangente, no seio da sociedade, a mulher aparece como o ser mais oprimido, mais humilhado, mais explorado. Ela é explorada pelo explorado, batida pelo homem rasgado pela palmatória, humilhada pelo homem esmagado pela bota do patrão e do colono (Idem).

Assim, falar do emponderamento da mulher na participação da vida económica, social e política é apegar-se sobretudo a mudança sociais e conquistas de direitos e de espaço público para actuação em todas as esferas e funções públicas. Ao longo das mudanças ocorridas na sociedade, a mulher deixou de exercer actividades somente no âmbito interno do lar (não que isso deixe de ter importância e seja respeitado quando por opção da mulher) para ocupar outros espaços antes ocupados somente pelo homem, dentre eles a política. Mas como seria possível fazer-se a Revolução sem que as mulheres estivessem mobilizadas e integradas no projecto?

Para que o projecto emancipatório se concretizasse e tivesse frutos desejados, era preciso mobilizar todos os explorados e oprimidos, por consequência as mulheres também. Esta Revolução para triunfar tinha que liquidar duma vez por todas o sistema de exploração e opressão, libertar todos os explorados e oprimidos, enfim, liquidar a exploração e a opressão da mulher, que era a obrigação sine qua non para a liberdade da mulher (MACHEL, 1973, p. 76).

Contudo, dizer-se que a mulher não sente a necessidade de se libertar, ou que muitas vezes é a FRELIMO, e não as mulheres, quem defende a emancipação destas, é um argumento vazio, se não resiste à análise. As mulheres sentem essa dominação, sentem a necessidade de modificar a sua situação social. o que existe é que a dominação exercida pela sociedade lhes asfixia as suas iniciativas, impede-lhes de exprimir as suas aspirações e visão futura da vida (Idem, p. 76).

No caso da Frelimo, a decisão política de que era preciso pensar na libertação das mulheres durante a luta de libertação nacional deu margem a acirrados debates. De modo especial no II $^{\circ}$ Congresso da Frente (1968) e na reunião do seu Comitê Central, em 1972. Alguns discursos de Samora Machel, publicados em livros de formação política e artigos da Tempo, permitiram obter uma noção da natureza deste debate.

Um desses discursos, publicado na íntegra, foi proferido por Machel na abertura da primeira Conferência das Mulheres Moçambicanas. Esse evento foi convocado pela Frente de Libertação, em 1973, e realizou-se na Tanzânia. O objectivo desta Conferência foi discutir a condição social das mulheres moçambicanas e pensar estratégias para a sua emancipação. Nessa 
Conferência estiveram reunidas mulheres de diferentes Províncias, profissões, condições sociais, idades e "etnias" - tanto do Norte quanto do sul de Moçambique, incluindo camponesas, professoras, enfermeiras, militares, estudantes, solteiras e casadas (MACHEL, 1979. p. 13-44).

Em seu discurso, Machel revelou alguns aspectos do debate que vinha ocorrendo sobre a mulher na Frelimo. O objectivo central da Conferência era o de estudar a questões inerentes à emancipação e engajamento da mulher, encontrar linhas de acção que a conduzirão à sua emancipação. Nesse contexto, iniciou sua fala com dois questionamentos que, possivelmente, devem ter aquecido a discussão entre seus membros. "Por que preocuparmo-nos com a emancipação da mulher? Qual a razão de convocarmos agora esta Conferência?”. Entre os membros da Frelimo, as opiniões variavam a esse respeito.

Segundo Machel (1973, p. 75), para uns, a prioridade naquele momento deveria ser a destruição das estruturas do colonialismo, sendo a emancipação das mulheres uma tarefa secundária e algo que deveria ser tratado após a independência e quando o país pudesse contar com uma base econômica, social e educacional sólida. Na visão de outros, investir na emancipação das mulheres exigia um sistema educacional estruturado, pois isso implicava não somente em alfabetizá-las, mas conscientizá-las das novas concepções relativas à identidade da mulher revolucionária, uma vez que a maioria ainda se encontrava muito "apegada à tradição" (MACHEL, 1973, p. 16-18). Alguns, ainda se utilizando dos Estatutos do Movimento, acreditavam ser necessário respeitar as práticas culturais locais, pois seu combate poderia ocasionar a perda de apoio das populações ao movimento de libertação nacional. Ademais, consideravam que não havia necessidade de investir nessa tarefa porque as mulheres não estavam sensibilizadas para isso. Tratava-se de algo artificial, uma invenção de alguns líderes da Frelimo imposta às mulheres. Depois de tornar pública essa diversidade de opiniões, Machel também comunicou a resolução desse debate.

\begin{abstract}
A libertação da mulher é uma necessidade fundamental da Revolução uma garantia de sua continuidade, uma condição de seu triunfo. A Revolução tem por objectivo essencial a destruição do sistema de exploração, a construção de uma nova sociedade libertadora das potencialidades do ser humano e que o reconcilia com o trabalho, com a natureza. É dentro deste contexto que surge a questão da emancipação da mulher. Não se pode liquidar só uma parte da opressão (...). Como fazer então a Revolução sem mobilizar a mulher? Se mais da metade do povo explorado e oprimido é constituído por mulheres, como deixá-las à margem da luta? A Revolução para ser feita necessita mobilizar todos os explorados e oprimidos, por consequência, as mulheres também (MACHEL,1979, p.18).
\end{abstract}

A Frelimo definiu a libertação da mulher como um compromisso inadiável. De uma forma geral, o princípio da emancipação da mulher esteve presente nos discursos dos governos socialistas 
em todo o mundo. Mas, ao invés de adiar o compromisso da emancipação para uma fase posterior da revolução, a Frente considerou que ele deveria ser simultâneo ao da libertação nacional e estruturação do socialismo. Além disso, afirmou o envolvimento das mulheres como uma necessidade vital do processo revolucionário.

Conforme o pensamento mais geral, a Frelimo também considerou que a exploração da mulher era parte integrante da exploração de classe presente na sociedade. Machel, em outro trecho do seu discurso, na abertura da Conferência das Mulheres Moçambicanas, evidenciou esta tendência:

\footnotetext{
A exploração da Mulher é um aspecto do sistema geral de exploração do homem pelo homem. E esta exploração que cria condições de alienação da mulher, a reduz à passividade e a exclui da esfera da tomada de decisões da sociedade. Assim, as contradições antagônicas que existem são entre a mulher e a ordem social exploradora. Estas contradições são as mesmas que opõem a totalidade das massas exploradoras do nosso país e do mundo às classes exploradoras (...) Só a Revolução é capaz de resolver definitivamente esta contradição porque só ela encarna os interesses das massas exploradoras, mobiliza, organiza e une para o combate, só ela é capaz de destruir a ordem social antiga. É a Revolução que instala no poder as massas exploradas, as massas que viviam oprimidas e eram forçadas à passividade (MACHEL, 1979, p. 18).
}

A forma de organização social tradicional permitiu às mulheres ocuparem o papel de produtoras. Em boa parte do continente africano, a organização das sociedades foi fortemente influenciada pelas relações de parentesco que tem como base o sistema de linhagens. Trata-se de um sistema variado e com um nível de predominância diferenciado nos espaços urbanos e rurais, porém podem apresentar alguns aspectos comuns. Baseia-se na descendência unilinear, isto é, na pertença de um indivíduo ao grupo de descendência (linhagem) e estabelece-se por filiação transmitida exclusivamente através do pai ou da mãe.

A Frelimo considerou que a emancipação feminina se efectivaria mediante o envolvimento das mulheres na estruturação da revolução. Todavia, em contradição ao pensamento de alguns socialistas, admitiu a necessidade de uma organização feminina que actuasse na mobilização das mulheres nesse novo processo, discutisse estratégias e lançasse mão de ações necessárias à concretização da sua emancipação, uma atitude singular em relação a outras experiências socialistas que julgavam desnecessária à formação de uma organização específica para tratar da questão das mulheres, uma vez que a questão de classe era considerada hegemônica. A Frelimo, antes mesmo da independência, convocou uma Conferência das Mulheres para discutir estratégias de emancipação feminina e, nessa mesma ocasião, fundou a Organização das Mulheres Moçambinas, a OMM, em 1973 (ALAMBERT, 1986, p. 1-128). 
Entre as políticas sociais do governo pós-independência, a emancipação das mulheres se destacou como uma das prioridades. Essa iniciativa resultou do fato da Frelimo, desde a sua formação (1962), ter definido a emancipação feminina como uma de suas diretrizes políticas, mas também de atuação que as mulheres tiveram durante o período da luta de libertação nacional, não se tratando simplesmente de uma política de concessão do novo governo.

\section{A influência das mulheres na participação política em moçambique}

A Constituição moçambicana estabelece claramente uma igualdade de sexo em todas as áreas da sociedade e proíbe qualquer discriminação legislativa, política, económica e social (Artigo 6, 67 e 69 da Constituição de Moçambique). Note-se, porém, que a Constituição não define o termo discriminação. Em Dezembro de 2004, a nova Lei de Família é uma ruptura clara com o passado e uma página nova na vida das mulheres. A Lei anterior estava baseada numa visão meramente patriarcal cimentada na desigualdade. Todas as associações que se reuniram com a missão enfatizaram o progresso trazido pela nova lei de família, com algumas raras excepções. Tais associações haviam contribuído para a sua adopção. Perante uma oposição cerrada, haviam travado uma batalha longa e dura pela aprovação da nova lei.

Neste caso, a luta dos movimentos feministas em relação a participação da mulher tem trazido hoje enormes benefícios a esse género, embora conscientes de uma grande "batalha" ainda por se travar neste sentido.

Por exemplo, na sociedade tradicional moçambicana, a mulher era vedada aos órgãos de tomadas de decisões, até porque elas não eram consideradas pessoas no sentido legal, não eram consideradas adultas independentemente da idade e não podiam falar em público, como nos dizem (ISAACMAN \& STEPHEM, 1984, p.11):

\footnotetext{
Segundo a lei consuetudinária, as mulheres não eram pessoas no sentido legal. Não podiam, por exemplo, comparecer em tribunais tendo sempre de ser representadas pelo seu tutor masculino. As mulheres passavam toda a sua vida sob a tutela de um dos membros masculinos mais velhos da linhagem a que pertenciam.
}

Este constitui, apenas um dos vários exemplos da situação da mulher na sociedade tradicional em relação a sua participação política na vida da sua comunidade e País. Esta situação, que foi se agravar ainda mais com a presença colonial em Moçambique, onde as mulheres como o género considerado mais fraco e sob tutela do membro masculino muitas vezes se viu abandonada a sua sorte quando o seu tutor masculino lhe era retirado para as plantações, ou para o serviço mineiro ou ainda como escravo. 
Descreve Isaacman (1984, p.112), que face a sua situação agravada, ainda mais com o colonialismo, a mulher não se intimidou e envolveu-se na resistência colonial, na cozedura de sementes como rejeição as culturas forçadas, lembrando ainda que a causa principal do levante no Barué que foi uma das resistências coloniais mais bem-sucedidas foi devido a violação das mulheres e o papel da jovem zambeziana a rainha Mbuia, que era tida como enviada divina para a protecção das mulheres. As mulheres foram ainda mais longe quando participaram na luta armada de libertação nacional, pegando em armas e combatendo lado a lado com os homens.

Entretanto, a nova lei estabelece uma total igualdade de género perante a lei, casamento, divórcio, a guarda das crianças, bem como na divisão de bens no casamento. Expressamente, exclui toda a discriminação contra a mulher, seja na área da poligamia, herança, idade para casar, opção das crianças, estatuto da viúva, etc. Requer que os maridos paguem uma pensão aos filhos no caso de divórcio. Os maridos já não são automaticamente considerados chefes de família com a autoridade paternal substituída pela autoridade parental.

As vantagens da lei também incluem;

- Igualdade do género na propriedade dos bens. Esta medida é crucial, visto que se aplica à propriedade da terra e, desse modo, tem um impacto directo no acesso à propriedade da terra por parte da mulher rural;

- A obrigação de registar o casamento tradicional ou religioso perante as autoridades civis para ter validade legal. Isso ajuda a mulher a ter acesso à justiça;

- A igualdade jurídica de todas as crianças nascidas no casamento e as nascidas fora do casamento incluindo as questões relacionadas com a herança e;

- Reconhecimento do casamento pela união de facto.

As mulheres se fizeram presentes na política contra o colonialismo português no período colonial. Em meados dos anos 60, elas também compuseram a coluna vertebral pegando em armas e juntos com vários homens lutarem frente em frente com o inimigo (colonialismo), em busca da sua liberdade. Neste momento, questões como sexualidade, corpo da mulher e a saúde, antes ditas apenas de esfera privada, são publicitadas pelo movimento feminista, surgindo uma linguagem inovadora e feminina. Esse movimento realizou enormes conquistas, principalmente, relacionadas à abertura do mercado de trabalho para a mulher. Porém, é comum perceber, em nossa realidade, a dupla ou tripla jornada de trabalho das mulheres que tem filhos e companheiros, pois além de 
trabalhar fora, tem que realizar os afazeres domésticos, comprometendo sua saúde e qualidade de vida.

As mulheres foram e continuam sendo objetos de opressão em todas as partes do mundo. Como vemos ao longo da história, são suprimidas do prazer sexual, da exibição do rosto, são escravizadas e prostituídas etc. No entanto, as mulheres conquistam cada vez mais seu lugar numa sociedade de forte resistência aos novos conceitos de gênero, protagonizando diversas causas femininas, reivindicando e discutindo questões que abordam esses conceitos.

É possível perceber com os estudos realizados até o momento que as mulheres ainda se deparam com significativas disparidades em vários aspectos sociais, culturais, econômicos e políticos e que os estudos realizados recentemente demonstram desigualdades entre homens e mulheres em diferentes espaços.

$\mathrm{Na}$ visão de Del Priore (2013, p. 90), refere que estudos demonstram, contudo, "a persistência de profundas desigualdades entre os dois sexos: econômica, política ou acesso aos postos de poder. Entre casais, a partilha de tarefas ainda é uma doce utopia; as mulheres consagramse três vezes mais que os companheiros às actividades domésticas".

Dessa maneira, a mulher contemporânea ainda vive em constante luta para alterar estereótipos, paradigmas e machismo de heranças tradicionais advindas de uma sociedade patriarcal, enfrentando desafios diários para conciliar tarefas de ordem pessoal, familiar e profissional. Percebemos que, mesmo diante de transformações significativas em diferentes espaços, muitas famílias continuam a eleger a mulher como referência para os trabalhos domésticos e os cuidados com os filhos, levando-nos a crer que o máximo conquistado foi um acúmulo de novas funções, fazendo com que as mulheres vivenciam desafios diários no que se refere à conciliação das tarefas de ordem pessoal, familiar e profissional.

No contexto moçambicano, vários representantes de grupos de mulheres enfatizam a resistência à mudança no tocante aos direitos dessas. A oposição à mudança está presente não somente entre os pobres e os analfabetos, mas também entre as pessoas educadas. Os motivos destas oposições incluem a salvaguarda das tradições como forma de preservação da identidade moçambicana. Muitos moçambicanos veem essas tradições como sendo muito típicas da cultura moçambicana e por isso devem ser fortificadas, não enfraquecidas. Finalmente, alguns sentem que as mulheres não devem abandonar o seu papel de conservadoras dessas tradições.

Berardino (2007) refere que "é preciso reconhecer que grandes conquistas foram obtidas. E, ainda que a mulher tenha muito caminho pela frente antes de conquistar a igualdade plena, o que já se fez até agora é irreversível. Não há como voltar aos “arranjos tradicionais” que limitavam 
as mulheres às paredes de seus lares, enquanto os homens exerciam, de forma exclusiva, o controle sobre tudo o que existia do lado de fora".

Houve progressos significativos na legislação, embora a aplicação prática desses continue insuficiente. Contudo, a protecção aos direitos sociais e económicos é pouca. O governo reconhece a situação, todavia diz que está incapaz de efectuar mudanças porque este problema, de acordo com o governo, é o resultado da situação de pobreza do país e da falta de fundos públicos para a realização de acções. A protecção dos direitos sociais e económicos das mulheres devem ser encarados como uma batalha difícil principalmente por causa da pobreza extrema em Moçambique.

Em relação à participação da mulher na vida pública e política, as mulheres em Moçambique estão mais representadas na política do que em muitos outros países Africanos 35,6\% das MPs (parlamentares) são mulheres: muitas ministras, vice-ministras, governadoras, directoras provinciais e várias administradoras, o que significa um ganho em relação a este cenário. Moçambique ainda não alcançou a igualdade de género na vida pública, apesar de o governo dizer que traçou uma política segundo o qual as mulheres solicitantes têm prioridade sobre os homens com as mesmas qualificações no tocante aos empregos do sector público. Os postos dos serviços civis continuam sendo dominados por homens.

Portanto, o combate aos estereotípicos machistas é o enteado desprezado da política do governo. Dificilmente é feito algo para mudar a maneira de pensar nesta área crucial. As imagens baseadas no papel tradicional do género são onipresentes e aparentemente nada está a ser feito para se mudar a representação da mulher nos mídias.

\section{Considerações finais}

O contrato social formador do Estado moderno, ou se quisermos do mundo político moderno, ao estabelecer uma esfera pública falsamente inclusiva, reduziu esses sujeitos a membros dotados de subcidadania e desprovidos de reconhecimento. A nossa tese é de que a esfera pública idealizada como projecto emancipatório construiu-se para o exercício do poder masculino, enquanto que a esfera privada foi legada à mulher. A submissão da mulher ao espaço privado (vida doméstica), sob vários pretextos, é a base de sua invisibilidade na história e na política. Daí a necessidade de reivindicar a cidadania para as mulheres e de liberá-las do fechamento na esfera privada.

A nossa tese é de que a ideologia desenvolvida pelo projecto emancipatório da mulher é considerada não positiva em termos de integração social e garantia dos direitos de todas as pessoas. Mas também negativa, por auxiliar na institucionalização das desigualdades e formação da 
subcidadania das mulheres. Por outro lado, a exclusão histórica e a inclusão desigual das mulheres na esfera pública tornam a crítica feminista crucial: Como sujeitos da teorização, as mulheres se debruçam sobre práticas que as marginalizam e narrativas que as silenciam.

Uma questão central desse debate é se o género aqui discutido é tratado ou analisado como problema político, se é incorporado apenas como variável demográfica ou se é completamente silenciado como dimensão das relações de poder e das experiências. É preciso compreender se e em que medida as teorias actualizam a dualidade entre a esfera pública e privada silenciando sobre as relações de poder na esfera doméstica e sobre o carácter patriarcal da esfera pública.

Pode-se concluir que é através das teorias feministas contemporâneas que as experiências das mulheres permitiram a redefinição das fronteiras entre o público e o privado. Por outro lado, é a partir delas que a divisão sexual do trabalho, a violência na vida familiar, a incidência diferenciada do controle do Estado sobre os corpos, assim como a acomodação entre noções abstractas de liberdade e condições socialmente toleradas de subordinação das mulheres, entre outros, vieram à tona como problemas políticos fundamentais da primeira ordem.

A participação das mulheres na cena política abre a possibilidade de discutir as representações sociais sobre os papéis sociais, colocando em xeque a hegemonia masculina no interior do próprio movimento. Os movimentos feministas conquistaram muitos avanços, principalmente no que se refere à entrada da mulher no mercado de trabalho e o acesso à cultura de um modo geral. Porém, as transformações sociais englobam várias dimensões da vida social, o que faz com que as mudanças tão almejadas ocorram de forma gradativa. Trata-se de uma luta pela liberdade, para além da equiparação de direitos, e pelo respeito à alteridade.

Actualmente no mundo, os movimentos feministas promovem uma luta constante de combate à violência doméstica, que, apesar das legislações punitivas existentes contra esta, são crescentes as ocorrências. Vários estudos sobre gênero também se colocam como tema de grande relevância, assim como os movimentos históricos e culturais das mulheres do país, que trouxeram muitas contribuições. Sumarizando, Moçambique já não é uma sociedade meramente tradicional e sérias mudanças na vida das mulheres estão a acontecer. Neste contexto, acelerar essas mudanças continua a ser um desafio, daí o papel do governo é criar condições e estratégias globais para mudar as relações de género, levando a cabo programas isolados que não são complementares. De modo a promover-se uma estratégia global, os lemas das mulheres devem estar ligados aos direitos humanos no geral. Habitualmente, os políticos moçambicanos veem nos direitos da mulher um pequeno aspecto dos direitos humanos. 
Uma das contribuições decisivas do pensamento feminista foi o questionamento da linha divisória entre a vida pública e privada, justamente para torná-la pública e, portanto, passíveis de serem reflectidas e debatidas as relações de dominação e exploração que até então eram obscurecidas pela privacidade do mundo privado ou doméstico. A privacidade da esfera privada, que sempre inclui as relações entre o chefe masculino da família e sua esposa e filhos, tem sido como um vidro opaco por meio do qual as mulheres e suas esferas tradicionais de actividade se tornam invisíveis e inaudíveis. Todas as feridas, para serem curadas, exigem a intervenção corajosa da juventude (homens e mulheres), moçambicanos, em particular, e africanos, em geral, para libertar, preservar, consolidar e desenvolver as conquistas do povo africano. Seria "inútil falarmos da emancipação dos povos quando África continua total ou parcialmente dependente das nações capitalistas cuja política visa essencialmente perpetuar a sua presença a partir da dominação económica e da temível arma de alienação cultural” (MODIBO \& NDIAYE, 2015, p. 396).

No nosso entender, a participação ativa das mulheres é indispensável à construção da democracia e da cidadania e assume um carácter crítico e prepositivo na construção das plataformas feministas dirigidas ao poder público. Esta actuação contribui para a elaboração de leis e para a administração pública, e para as candidaturas político-partidárias, no sentido de sensibilização e estabelecimento de compromissos das/os candidatas/os. Muitas de suas ações têm produzido desdobramentos concretos em termos de inovações e conquistas legislativas e de políticas públicas.

Em suma, um dos grandes desafios para o progresso das mulheres parece ser o de enfrentar a distância ainda grande entre o reconhecimento formal dos direitos à participação e a divisão de tarefas que efectivamente ocorre entre mundo público e vida privada. Um outro desafio pode ser o de encarar o poder e seus diversos espaços como algo positivo, e não apenas na sua condição de exterioridade para as mulheres. Incluir como estratégia o estímulo e a disputa pela ocupação de cargos pelas mulheres nos espaços públicos e administrativos, espaços de interesse colectivo como sindicatos e associações ou mesmo espaços de decisão privada como empresas é parte da caminhada por equidade. Mas deve ser concomitante a um terceiro bloco: a mudança da cultura de gênero ainda tradicional quanto aos papeis e expetativas e que são disseminados ou explícita ou sutilmente na mídia, nas relações interpessoais e institucionais.

As mulheres e homens jovens têm a missão de não apenas exigir e obter a reforma e a democratização do ensino nas escolas africanas para se adaptar às necessidades básicas do nosso povo e das exigências do mundo contemporâneo. Basta de sermos apenas simples espectadores passivos da história, não devemos encontrar motivos de satisfação na mediocridade, caso contrário a história nos julgará e os nossos bisnetos nos crucificarão severamente pela terceira vez. Não 
devemos ser presa fácil das influências malévolas, das manipulações exteriores, pois não é imitando o comportamento de outras pessoas, ou aceitando um status menos, que poderemos construir a nossa dignidade humana como africana e a África que sonhamos e satisfazer rapidamente a esperança de nossos povos por uma vida de liberdade, dignidade e bem-estar colectivo. Finalmente, todos os jovens devem ser patriotas se pretendem construir um Estado independente, uma África estável, mais unida e mais forte, uma África livre das doenças, da ignorância, das guerras, da pobreza e da fome. Uma África enobrecida pela justiça, liberdade e dignidade humana.

\section{Referências}

BENHABIB, Seyla. O outro generalizado e o outro concreto. A controvérsia Kohlberg-Gilligan e a teoria feminista. In. BENHABIB, Seyla, Cornell, Drucilla (coord.). Feminismo como crítica da modernidade. RJ. Rosa dos Tempos, 1987, pp. 87-106.

BENHABIB, Situating the Self: Gender, Community and post-modernism in contemporary ethics. Cambridge, UK, Polity Press, 1992.

BIROLI, Flávia. Divisão sexual do trabalho e democracia. DADOS - Revista de Ciências Sociais, Rio de Janeiro, vol. 59, no 3, 2016, pp. 719 a 681.

CASIMIRO, ISABEL. Paz na Terra, Guerra em Casa. Série Colecção Brasil e África. Editora UFPE, 2014.

CONCEIÇÃO, da Íris \& QUENANE, José Reich, Representação Política das Mulheres no Parlamento Moçambicano Análise sobre o Acesso e Exercício do Poder Legislativo, 2004- 2012, Maputo, 2013.

ENI, Orlandi. As reformas do Silêncio no movimento dos sentidos. Campinas, Ed. Unicamp, 2002.

FRAZER, Nancy. Rethinking the public sphere: a contribution to the critique of actually existing democracy. In: Calhon Craig (ed). Habermas and the public sphere. Cambridge, MIT Press, 1992, pp.109-142.

HABERMAS, Jürgen. Mudança Estrutural da Esfera Pública. São Paulo, UNESP, 2014.

MODIBO, Sheik Dadiarra \& NDIAYE, B. Moustafa Cheikh. O menosprezo ocidental, Lágrimas de Sangue: Contos e contos da escravidão. Senegal, CCM, Brasil, 2015.

NIETZSCHE, F. W. O nascimento da tragédia, ou Helenismo e Pessimismo. Tradução J. Guinsburg. São Paulo, Companhia das Letras, 1992.

PATEMAN, Carole. The dissorder of Women: Democracy feminism and political theory. Stanford, Stanford University Press, 1989.

SERRA, Andrea. Survey on the status of Business Women in Mozambique, Maputo, IFC.

http://www.revistamirabilia.com/Numeros/ Num3/artigos/art9.htm. 2007. consultada em 28$03-20$. 
CHINGORE, Tiago Tendai. Empoderamento e equidade de género: os desafios atuais da mulher

VVaa. Samora M. Machel: História de uma vida dedicada ao povo moçambicano. Maputo, ARPAC-IISC, 2014.

VIDAL, Sara. A participação positiva das mulheres em Moçambique e na Tanzânia: Um estudo comparativo. Dissertação de Mestrado. Lisboa, IU, 2017. 